\title{
INTESTINAL OBSTRUCTION CAUSED BY HYDRONEPHROSIS
}

\author{
C. S. Lygonis, M.D. \\ Surgical Registrar, St. Giles' Hospital, Camberwell, Lonton, S.E.5*
}

Compression of the bowel by a large hydronephrosis is an unusual cause of acute intestinal obstruction. In view of the rarity of this condition, the following two examples are reported briefly.

Case I.-Mrs. S. L., aged 72 years, was admitted to hospital with a three-day history of severe abdominal pain and vomiting: she had had no bowel-action for two days. Examination showed an ill-looking woman, with temperature $99^{\circ} \mathrm{F}$., pulse ı00, B.P. 170/70. The abdomen was very distended, and a large, tender mass was palpable on the right side of the abdomen. Bowel sounds were exaggerated. Nothing abnormal was detected on rectal examination. Radiography confirmed the diagnosis of intestinal obstruction.

At laparotomy, through a right paramedian incision, the ascending colon was found to be obstructed by a large, loculated cystic mass which was compressing it against the anterior abdominal wall. After division of adhesions the colon was freed from the front of this mass, which was then identified as a hydronephrotic right kidney. Nephrectomy was performed. The patient made an uneventful recovery from this operation, leaving hospital two weeks later.

Case 2.-Mrs. A. R., aged 78 years, was admitted to hospital with a five-day history of abdominal pain and vomiting. For four weeks prior to this she had experienced colicky pain in the right iliac fossa. Her bowels, usually regular, had not been open for four days prior to admission. Examination showed a pale, ill-looking woman: pulse 100, B.P. 190/100. The abdomen was distended, with a large, tender mass in the right iliac fossa. Bowel sounds were exaggerated. Hæmoglobin $78 \%$, blood urea $60 \mathrm{mg} . / 100 \mathrm{ml}$.

A provisional diagnosis of intestinal obstruction was made, and laparotomy carried out through a right paramedian incision. In the right iliac fossa the cæcum was found to be adherent to the previously noted mass, which was compressing it against the anterior abdominal wall. After mobilization of the cæcum, the mass was identified as a hydronephrotic right kidney, and nephrectomy was performed. 'The patient's immediate recovery from operation was satisfactory, but she died two weeks later with a blood-urea concentration of $590 \mathrm{mg}$./ $100 \mathrm{ml}$.

\section{Discussion}

The manifestations of intestinal obstruction are too well known to warrant discussion, and the interest of these cases lies in the rarity of the cause of the obstruction. In both the cases reported here the colon was adherent to the hydronephrosis, thus presumably preventing displacement of the bowel and so leading to its compression against the anterior abdominal wall. It is of interest that in neither case was there any history of previous renal trouble.

In his well-known monograph on intestinal obstruction, Wangensteen (1955) mentions a large hydronephrosis as being amongst the causes of intestinal obstruction from compression of the bowel. Reports of single examples of the condition have appeared from time to time in foreign literature (Volteranni, 1957; Rajmon, 1957), but there appears to be no previous report of this condition in British literature.

\section{Summary}

Two cases of intestinal obstruction due to external compression by an hydronephrosis are reported.

My thanks are due to Mr. Iain Matheson for permission to report one of the cases.

\section{REFERENCES}

Rajmon, J. (1957): Subileus durch enorme Hydronephrose, Zbl. Chir., 82, 779.

VolteranNi, A. (1947): Occlusione intestinale acuta da idronefrosi congenita del rene sinistro ectopica, Policlinico, Sez. prat, 54, 325.

WANGENSTEEN, O. H. (1955): 'Intestinal Obstruction'. Springfield, Illinois: Charles C. Thomas.

*Present address: 75, Skoufa Street, Athens, Greece. 